\title{
Have the roles of two functional polymorphisms in breast cancer, R72P in P53 and MDM2-309 in $M D M 2$, become clearer?
}

\author{
Rodney J Scott* \\ See related research by Schmidt et al., http://breast-cancer-research.com/content/11/6/R89
}

\begin{abstract}
Genetic differences between individuals have been predicted to account for disparate outcomes in patients diagnosed with cancer. The search for genetic determinants has been ongoing for a considerable amount of time and it is only now that insights have been gained into which polymorphisms are most likely to be important in determining not only disease likelihood but also outcome. The quest to be able to accurately predict patient outcomes in breast cancer may now be a step closer as increased sample size is leading to more robust statistical analysis and a better understanding of molecular mechanisms of disease are forthcoming.
\end{abstract}

Predicting disease outcome after the diagnosis of breast cancer, which is important for the choice of treatment of women diagnosed with this malignancy, remains a major challenge. Over the past decade there has been an increasing awareness of the power of genetic prediction, which is now beginning to provide some information that may be useful in the assessment of disease outcome. As an example, several reports in the literature indicate that genetic signatures are potentially useful approaches for prognostication. A major impediment to rapid progress in the identification of genetic determinants of outcome has been, and continues to be, our limited ability to assess gene-gene and gene-environment interactions. Nevertheless, inroads into understanding gene-gene interactions

*Correspondence: rodney.scott@newcastle.edu.au

Discipline of Medical Genetics, Faculty of Health, University of Newcastle Newcastle, NSW 2308, Australia; Centre for Information Based Medicine, Hunter Medical Research Institute, John Hunter Hospital, Newcastle, NSW 2305, Australia and Division of Genetics, Hunter Area Pathology Service, John Hunter Hospital, Newcastle, NSW 2305, Australia are being made due, in part, to a better appreciation of molecular pathway analysis. Particularly attractive targets of study have been genetic polymorphisms in genes associated with the repair of DNA damage and those involved in cell cycle control since an inability to tightly regulate either of these two processes is likely to result in a less than optimal outcome.

In the report by Schimdt and colleagues [1] the genegene interaction between the cell cycle checkpoint control gene P53 and its negative regulator MDM2 has been examined in a large group of women diagnosed with breast cancer to determine whether two single nucleotide polymorphisms (SNPs), R72P in P53 (rs1042522) and MDM2-309 (rs2279744), could be associated with disease outcome. This is not the first study to examine the relationship between the tumour suppressor gene P53 and MDM2, but it is one of the first to investigate the relationship between polymorphisms in these genes and disease outcome as opposed to breast cancer risk. The importance of the two SNPs lies in their functional consequence. R72 is reported to have a 15 -fold greater capacity to induce apoptosis than P72 [2] and the MDM2 polymorphism has been shown to be associated with deficiencies in the P53 response pathway [3].

Studies examining the relationship between R72P and MDM2-309 and cancer risk have been somewhat inconsistent, but many larger studies examining common malignancies (including breast cancer) are converging towards the notion that neither SNP appears to be associated with the risk of developing disease [4-8]. These results are in contrast, however, to investigations into cancers developing in patients diagnosed with germline P53 mutations, where both R72P and MDM2-309 SNPs do appear to be associated with differences in the age at which disease is diagnosed $[3,9,10]$. This is perhaps not surprising as loss of P53 will underlie subsequent events associated with tumour development in this setting.

The pooled analysis presented by Schmidt and colleagues [1] of four studies, three hospital- and one 
population-based, including 3,749 breast cancer patients, provided sufficient power to detect whether or not there were any associations between the combined polymorphisms and disease outcome. The results revealed that there is an association between the two SNPs and breast cancer outcome, suggesting that they could be used as potential markers to stratify patients into different risk groups. Nevertheless, even with this large number of patients only 26 were homozygous for both variants, thereby making it impossible to quantify statistically the strongest effect. This emphasizes the necessity of acquiring large numbers of patients for genetic studies since smaller ones run the risk of having insufficient power to detect these types of effect. The magnitude of the effect, however, remains relatively small (with an $11 \%$ difference) and emphasises the point that these two markers account for only some of the differences between patients with good or poor survival.

Previously, Schmidt and colleagues [8] had demonstrated for breast cancer that neither R72P nor MDM2-309 was associated with the risk of developing disease, which was supported by several other larger studies [4-7]. Placing this in context, the results of Schmidt and colleagues [1] are significant as they indicate that R72P and MDM2-309 act as affect modifiers as opposed to being causal. If R72P and MDM2-309 are indeed affect modifiers, then further studies in different populations should yield similar results as the effects of the two SNPs would be predicted to be similar in diverse groups of patients. In support of this, the results are consistent with a report by Do and colleagues [11], who identified that both polymorphisms also act as disease modifiers in lymphoblastic leukaemia.

Since the advent of gene expression array technology, it is now well recognised that there are multiple subgroups of breast cancer that can be characterised not only by their histopathology but also by gene expression profiling and that these differences are correlated with disease survival [12-14]. In relation to R72P and MDM2-309, it would be predicted that these two SNPs, acting as disease modifiers, are likely to remain associated with survival even in different subgroups of patients as they would still remain affect-modifiers and continue to contribute to disease progression irrespective of the molecular profile of the tumour.

Finally, this study and those that have preceded it raise important points in relation to the choice of disease in which to examine polymorphisms in two key regulators of cell cycle checkpoint control. If one of the primary molecular alterations involves P53, then it is to be expected that differences in the remaining wild-type $P 53$ allele (or its downstream partners) will be influenced by intrinsic functional polymorphisms, which are likely to correlate with the age at disease diagnosis. If P53 is not involved in a disease's initiation but in its progression, then it is more prone to be associated with differences in prognosis. The report by Schmidt and colleagues [1] has significantly contributed to our understanding of risk recurrence in patients diagnosed with breast cancer. It is to be expected that with larger, more definitive studies, more precise information about the role of R72P and MDM2-309 in disease outcome will be forthcoming.

\section{Abbreviations}

SNP = single nucleotide polymorphisms.

\section{Competing interests}

The author declares that he has no competing interests.

Published: 3 February 2010

\section{References}

1. Schmidt Mk, Tommiska J, Broeks A, van Leeuwen FE, van't Veer LJ, Pharoah PDP, Easton DF, Shah M, Humphreys M, DörkT, Reincke SA, Fagerholm R, Blomqvist $\mathrm{C}$, Nevanlinna $\mathrm{H}$ : Combined effects of single nucleotide polymorphisms TP53 R72P and MDM2 SNP309, and p53 expression on survival of breast cancer patients. Breast Cancer Res 2009, 11:R89.

2. Dumont P, Leu Jl, Della Pietra AC 3rd, George DL, Murphy M: The codon 72 polymorphic variants of p53 have markedly different apoptotic potential. Nat Genet 2003, 33:357-365.

3. Bond GL, Hu W, Bond EE, Robins H, Lutzker SG, Arva NC, Bargonetti J, Bartel F, Taubert H, Wuerl P, Onel K, Yip L, Hwang S-J, Strong LC, Lozano G, Levine AJ: A single nucleotide polypmorphism in the MDM2 promoter attenuates the p53 tumor suppressor pathway and accelerates tumor formation in humans. Cell 2004, 119:591-602.

4. Cox DG, Deer D, Guo Q, Tworoger SS, Hankinson SE, Hunter DJ, De Vivo I: The p53 Arg72Pro and MDM2-309 polymorphisms and risk of breast cancer in the nurses' health study. Cancer Causes Control 2007, 18:621-625.

5. Campbell IG, Eccles DM, Choon DYH: No association of the MDM2 SNP309 polymorphism with risk of breast or ovarian cancer. Cancer Lett 2006, 240:195-197.

6. Idbaih A, Boisselier B, Marie Y, Sanson M, Hallani SE, Crinière E, Fourtassi M, Paris S, Carpentier C, Rousseau A, Mokhtari K, Combadière C, Laigle-Donadey F, Delattre J-Y: Influence of MDM2 SNP309 alone or in combination with the TP53 R72P polymorphism in oligodendroglial tumors. Brain Res 2008, 1198:16-20.

7. Alhopuro P, Ylisaukko-oja SK, Koskinen WJ, Bono P, Arola J, Järvinen HJ, Mecklin J-P, Atula T, Kontio R, Mäkitie AA, Suominen S, Leivo I, Vahteristo P, Aaltonen L-M, Asltonen LA: The MDM2 promoter polymorphism $\mathrm{SNP309T} \rightarrow \mathrm{G}$ and the risk of uterine leiomyosarcoma, colorectal cancer, and squamous cell carcinoma of the head and neck. J Med Genet 2005, 42:694-698.

8. Schmidt MK, reincke S, Broeks A, Braaf LM, Hogervorst FBL, Tollenaar RAEM, Johnson N, Fletcher O, Peto J, Tommiska J, Blomqvist C, Nevanlinna HA, Healey CS, Dunning AM, Pharoah PDP, Easton DF, Dörk T, Van't Veer $L$, on behalf of the Breast Cancer Association Consortium. Do MDM2 SNP309 and TP53R72P interact in breast cancer susceptibility? A large pooled seires from the breast cancer association consortium. Cancer Res 2007. 67:9584-9590.

9. Bougeard G, Baert-Desurmont S, Tournier I, Vasseur S, Martin C, Brugieres L, Chompret A, Bressac-de Paillerets, Stoppa-Lyonnet D, Bonaiti-Pellie C, Frebourg T. Impact of the MDM2 SNP309 and p53 Arg72Pro polymorphism on age of tumour onset in Li-Fraumeni syndrome. J Med Genet 2006, 43:5310-5313.

10. Ruijs MWG, Schmidt MK, Nevanlinna H, Tommiska J, Aittomaki K, Pruntel R, Verhoef S, van't Veer $L$ J: The sinlge-nucleotide polymorphism 309 in the MDM2 gene contributes to the Li-Fraumeni syndrome and related phenotypes. Eur J Hum Genet 2007, 15:110-114.

11. Do TN, Ucisik-Akkaya E, davis CF, Morrison BA, Dorak MT: TP53 R72P adn MDM2 SNP309 polymorphisms in modification of childhood acute lymphoblastic leukemia susceptibility. Cancer Genet Cytogenet 2009, 195:31-36. 
12. Sorlie T, Perou CM, Tibshirani R., Aas T, Geisler S, Johnsen H, Hastie T, Eisen MB, van de Rijn M, Jeffrey SS, Thorsen T, Quist H, Matese JC, Brwon PO, Botstein D, Lønning PE, Børresen-Dale A-L: Gene expression patterns of breast carcinomas distinguish tumor subclasses with clinical implications. Proc Natl Acad Sci 2001, 98:10869-10874.

13. Wang Y, Klijn JGM, Zhang Y, Sieuwerts AM, Look MP, Yang F, Talantov $D$, Timmermans M, Meijer-van Gelder ME, Yu J, Jatkoe T, Berns EMJJ, Atkins D, Foekens JA: Gene-expression profiles to predict distant metastasis of lymph-node-negative primary breast cancer. Lancet 2005, 365:671-679.
14. Fan C, Oh DS, Wessels L, Weigelt B, Nuyten DSA, Nobel AB, van't Veer L, Perou $\mathrm{CM}$ : Concordance among gene-expression-based predictors for breast cancer. N Engl J Med 2006, 355:560-569.

doi:10.1186/bcr2474

Cite this article as: Scott RJ: Have the roles of two functional

polymorphisms in breast cancer, R72P in P53 and MDM2-309 in MDM2,

become clearer? Breast Cancer Research 2010, 12:102. 